\title{
Phylogenetic analysis of secondary metabolites in a plant community provides evidence for trade-offs between biotic and abiotic stress tolerance
}

\author{
Alicia Montesinos-Navarro ${ }^{1} \cdot$ Rosa M. Pérez-Clemente ${ }^{2} \cdot$ Ricardo Sánchez-Martín $^{1}$. \\ Aurelio Gómez-Cadenas ${ }^{2} \cdot$ Miguel Verdú ${ }^{1}$
}

\begin{abstract}
Plants' responses to conflicting stresses may result in physiological trade-offs due to the inter-dependent and costly nature of physiological investments. Physiological tradeoffs have been proved within species, but to what extent these trade-offs are the result of phylogenetic constraints remains poorly known. Environmental stresses can vary widely in different biomes, and therefore assessing physiological tradeoffs across species must account for this variation. One way of doing so is to assess it within a community, where the co-occurring species have faced a shared combination of filters to establish. Considering a representative sample of species in a single community, we use a macroevolutionary approach to test the hypothesis that plant physiological trade-offs are evolutionarily conserved within this community (i.e., closely-related species tend to solve the trade-offs similarly). We analyze the content of five metabolites in thirty co-occurring plant species, capturing their range of contrasting exposures to abiotic and biotic stresses (growing solitary and in vegetation patches). Our results support that species investment in response to abiotic stress (i.e., proline and abscisic acid content) is traded off against their investment to face biotic stress (i.e., jasmonic acid and salicylic acid), shown by the contrasting loadings of these two groups of metabolites in the first axes of a principal component analysis (PCA). In addition, the metabolic strategies observed in this community are evolutionarily conserved, as closely related species tend to have similar scores in this PCA, and thus resemble each other in their balance. This is shown by a significant phylogenetic signal in the species' scores along the first axes of the PCA. Incorporating the evolutionary history of plant species into physiological studies can help to understand the response of plants to multiple stresses currently acting in ecological communities.
\end{abstract}

Keywords Biotic-abiotic stress · Gypsum outcrops · Metabolic tradeoffs · Phylogenetic signal $\cdot$ Plant facilitation $\cdot$ Stress

Electronic supplementary material The online version of this article (https://doi.org/10.1007/s1068 2-020-10044-2) contains supplementary material, which is available to authorized users.

* Alicia Montesinos-Navarro ali.montesinos@gmail.com 


\section{Introduction}

Plants simultaneously deal with stresses of multiple origins, which might require a differential prioritization of some stress-responses against others to maximize fitness. The optimal solution to these trade-offs might be constrained by the evolutionary history of the species, in a similar way that plant responses to a single stress, such as herbivory, are macroevolutionary constrained (Pearse et al. 2017). The balance in the investments to face multiple stresses has received considerable attention within species (Eränen et al. 2009; Ariga et al. 2017; Berens et al. 2019; Pihain et al. 2019), for instance showing genetic correlations between alleles related to osmotic stress tolerance, and resistance to aphids and caterpillars (Thoen et al. 2017). However, as far as we know, it remains unknown whether the response of plants to multiple stresses is phylogenetically constrained, resulting in speciesspecific combinations of metabolic profiles that tend to resemble between closely related species. As the diversity and magnitude of different stresses vary across biomes, potential evolutionary constraints might only emerge when differences across environments are taken into account. Therefore, a first step would be to approach these evolutionary constraints within a community, where the co-occurring species have shared a combination of filters to establish.

Plants can respond to abiotic and biotic stress through different physiological mechanisms. Some plant physiological responses can be simultaneously associated with both biotic and abiotic stress, like an increase in indole acetic acid (IAA) (Epstein and Ludwig-Müller 1993), which can induce root development and growth in response to either water stress or root damage due to pathogens or herbivores. However, other physiological responses are likely related to either biotic or abiotic stresses. It is widely accepted that abscisic acid (ABA) is the main hormone controlling the stomata opening under water stress conditions (Sah etal. 2016; Gómez-Cadenas etal. 2015; Munemasa etal.2015) and it is key for the adaptation to dry environments. Similarly, a thoroughly described plant response to limited water availability is to accumulate proline to adjust osmotic potentials (e.g., Dobra et al. 2010). On the other hand, biotic stresses caused by arthropod herbivores and necrotrophic pathogens induce jasmonic acid (JA) accumulation, as shown elsewhere (Glazebrook 2005; Bosch et al. 2014; Erb et al. 2012), which is involved in plant resistance to these pathogens. It is also well-known that salicylic acid (SA) is vital for the establishment of the systemic acquired resistance (SAR), an immune response of plants that provides long-lasting protection to infection by a broad spectrum of phytopathogens (Hartmann and Zeier 2019; Klessig et al. 2018). Nevertheless, recently ithas been shown that phytohormone signaling to abiotic and biotic stresses (i.e., ABA and SA) can be compromised, for instance showing a differential prioritization along time (Berens et al. 2019). Trade-offs between plant responses to biotic/abiotic stress may also result from investing in the production of one metabolite at the expense of other defenses, such as reducing proline biosynthesis may induce the increase of lignin content (Guan et al. 2019).

Plant communities shaped by facilitation provide a convenient scenario to capture species variation in response to multiple stresses for two reasons. On the one hand, plant facilitation is prevalent in arid ecosystems where the abiotic stress is severe. Nurse plants alleviate abiotic stress by providing shade, moisture, and nutrients to the shared rhizosphere, facilitating the establishment of other species (Foronda et al. 2019). Although facilitated species find a milder abiotic microhabitat under nurse plants, they also cope with new neighbors that might impose increasing biotic stress (Ristok et al. 2019). Therefore, an increase of biomass in vegetation patches, compared to plants growing solitary, can trigger 
attraction to pathogens with low host specificity, such as fungi (Gilbert and Webb 2007; Kluger et al. 2008; Hersh et al. 2012; Spear and Mordecai 2018), or herbivores (Novotny and Basset 2005). In this sense, clearly defined microhabitats in ecosystems governed by facilitation (i.e. growing solitary vs. in a vegetation patch) provide a wide range of ecological contexts from the abiotic stressful bare ground to the biotic stressful environments driven by plant neighbors and their associated pathogens and herbivores. Thus, conspecific individuals growing in these contrasting conditions can be considered to provide a range of variability of plantresponses to biotic and abiotic stresses. On the other hand, environmental stresses can vary widely in different biomes, and therefore physiological trade-offs across all the angiosperms might be blurred by these differences. Plant communities, like those governed by facilitation, provide a set of species that have been co-occurring in the same community for long periods, facing a shared combination of filters to establish. This scenario prevents the mixture of contrasting macro-environmental conditions, resulting in a convenient framework to assess potential evolutionary constraints in plant responses to multiple stresses.

Here, we profited from a Mediterranean semiarid environment where facilitative interactions generate contrasting ecological conditions by structuring the plant community in vegetation patches (Delalandre and Montesinos-Navarro 2018). In this system, we test whether plant species show a trade-off in their investment in metabolites related to abiotic and biotic stress tolerance. Specifically, we expect that if that trade-off exists, those species with a higher investment in proline and ABA (associated with responses to abiotic stress) will show lower levels of JA and SA (associated with biotic stress) and vice versa. In case there is evidence supporting our first hypothesis, we will also test whether this trade-off is evolutionarily conserved across the plant species that co-occur in the community. Understanding potential trade-offs in the metabolic responses across coexisting plant species can contribute to link evolutionary and physiological processes taking place at the community level.

\section{Materials and methods}

\section{Study site and field sampling design}

We performed the study in gypsum outcrops located within $20 \mathrm{~km}^{2}$ in Eastern Spain (38 $29^{\prime} \mathrm{N}, 0^{\circ} 44^{\prime} \mathrm{O}$; elevation: $568 \mathrm{~m}$ ). The climate is semi-arid, with an annual mean rainfall of $414 \mathrm{~mm}$, and a variation of $55 \mathrm{~mm}$ between the driest and the wettest months. Mean daily maximum and minimum temperatures range from 3.3 to $13.3^{\circ} \mathrm{C}$ in January, and from 18.4 to $30.6{ }^{\circ} \mathrm{C}$ in August. The plant community is a scrubland with abundant chamaephytes such as Helianthemum squamatum (L.) Dum. Cours., Teucrium libanitis Schreb. and Helianthemum syriacum (Jacq.) Dum.Cours. (Delalandre and Montesinos-Navarro 2018).

Plant sampling took place in November 2018. We selected the most representative thirty plant species in the gypsum outcrops. This design includes all the dominant species (Delalandre and Montesinos-Navarro 2018), and around $80 \%$ of the species of the community. The number of species used (30 species) responds to the ecological constraint of the species richness of the community and, although it represents a very small proportion of all the angiosperms, it properly characterizes almost all the species present in the studied community. Phylogenetic comparative methods can be used for different purposes. 
Therefore, while the assessment of a phylogenetic signal can explore evolutionary patterns across broad taxonomic levels (Gómez et al. 2010; Werner et al. 2014), it has also been widely applied to assess the phylogenetic basis of niche differentiation at the community level (Webb et al. 2002) and explore the ecological and evolutionary mechanisms underlying this differentiation (Ackerly 2003), progressively improving its correct implementation (Münkemüller et al. 2015). In order to contextualize the magnitude of our sample size, we can compare it with previous studies that have also tested for a phylogenetic signal in other plant traits within a community. Focusing on plant traits related to plant-soil feedback, phenology, flammability, plant-mycorrhizal interactions or germination, most of the studies considering a particular community used similar sample sizes as our study, ranging from 17 to 60 plant species (Anacker et al. 2014; CaraDona and Inouye 2015; Simpson et al. 2016; Li et al. 2017; Chen et al. 2017; Salazar et al. 2018). Only in two studies, the sample size was above 100 species which corresponded to megadiverse ecosystems such as the Brazilian Atlantic forest or subtropical rainforest in Taiwan (Chang-Yang et al. 2016; Gastauer et al. 2017). Whether the phylogenetic signal was significant or not depended on the specific trait analyzed rather than on the sample size, as some studies with only 17 plant species found a significant signal while others with more than 30 species found nonsignificant phylogenetic signals (Montesinos-Navarro et al. 2012; Nagahama and Yahara 2019). As our design covers most of the species in the community studied, we consider that the 30 species analyzed can properly characterize the constraints among those species that have shared the same environmental filters present in the selected ecosystem.

For each species, we sampled a pair of individuals of a similar size, each of them in: (a) a harsh abiotic environment with low biotic stress (i.e., on the bare ground), and (b) a milder abiotic microhabitat with increasing biotic stress imposed by neighbors (i.e., in a vegetation patch). This sampling pursues to maximize the intraspecific variation captured for each species. We collected $10 \mathrm{~g}$. of fresh leaf tissue for each individual within four hours on a single day avoiding water loss by refrigerating them during the whole process, and froze them at $-20{ }^{\circ} \mathrm{C}$ until we analyzed the samples. Every plant sampled seemed healthy and showed no sign of pathogen infection or herbivory.

\section{Metabolite analyses}

\section{Proline concentration}

We performed proline analysis as described by Bates et al. (1973) with some modifications. We extracted $50 \mathrm{mg}$ of ground frozen leaf tissue by sonication for $30 \mathrm{~min}$ in $5 \mathrm{ml}$ of $3 \%$ sulfosalicylic acid (Panreac, Barcelona, Spain). After centrifuging at $4000 \times g$ at $4^{\circ} \mathrm{C}$ for $20 \mathrm{~min}$, the supernatant was mixed with glacial acetic acid and ninhydrin reagent (Panreac) in a 1:1:1 proportion (v:v:v). We incubated the reaction mixture at $100^{\circ} \mathrm{C}$ for $1 \mathrm{~h}$. After centrifugation at $2000 \times \mathrm{g}$ at $4{ }^{\circ} \mathrm{C}$ for $5 \mathrm{~min}$, proline concentration was spectrophotometrically determined at $520 \mathrm{~nm}$. We performed a standard curve with pure proline (Sigma-Aldrich, St. Louis, MO, USA).

\section{Phytohormone analysis}

We carried out hormone extraction and analysis as described in Durgbanshi et al. (2005) with few modifications. Briefly, $100 \mathrm{mg}$ of ground frozen leaf tissue was extracted in $2 \mathrm{~mL}$ of ultrapure water using a mill ball equipment (MillMix20, Domel, Železniki, Slovenija) 
after spiking with 50 ng of $\left[{ }^{2} \mathrm{H}_{6}\right]-\mathrm{ABA},\left[{ }^{13} \mathrm{C}_{6}\right]-\mathrm{SA}$, dihydro jasmonic acid (DHJA) and $\left[{ }^{2} \mathrm{H}_{2}\right]$-IAA. Samples were centrifuged at $4000 \times g$ for 10 min at $4{ }^{\circ} \mathrm{C}$ after the extraction and supernatants were recovered and $\mathrm{pH}$ adjusted to 2.8-3.2 with acetic acid. We partitioned the extracts twice against $2 \mathrm{~mL}$ of diethyl-ether and the organic layer evaporated under vacuum in a centrifuge concentrator (Speed Vac, Jouan, Saint Herblain Cedex, France). The residue was resuspended in $0.5 \mathrm{~mL}$ of methanol: water 10:90 and filtered through $0.22 \mu \mathrm{m}$ polytetrafluoroethylene membrane syringe filters (Albet S.A., Barcelona, Spain) and directly injected into an ultra-performance liquid chromatography system (Acquity SDS, Waters Corp., Milford, MA, USA). Chromatographic separations were carried out on a reversed-phase C18 column (Gravity, $50 \times 2.1 \mathrm{~mm} 1.8-\mu \mathrm{m}$ particle size, MachereyNagel GmbH, Germany) as stationary phase using a methanol:water (both supplemented with $0.1 \%$ acetic acid) gradient at a flow rate of $300 \mu \mathrm{L} \mathrm{min}^{-1}$ as mobile phase. We quantified hormones with a triple quadrupole mass spectrometer (Micromass, Manchester, UK) connected online to the output of the column through an orthogonal Z-spray electrospray ion source.

\section{Statistical analyses}

Toassess the combination of the five metabolites contents that best explain the variation observed across individuals, we performed a phylogenetic principal component analysis. Non-phylogenetic principal component analyses assume that the sample consists of independent data points, which is likely violated by phylogenetic data from related species. If phylogeny is ignored, type I error of the statistical estimators and hypothesis tests can be increased, which can be avoided using phylogenetic principal component analyses (Revell 2009). However, these procedures provide residuals and scores in the original, phylogenetically dependent, species space, instead of in a phylogenetically independent space, so that the scores from these analyses can still be analyzed to explore phylogenetic patterns (Revell 2009). For three out of the thirty species, the values of SA were one order of magnitude larger (Santolina chamaecyparissus: 5386.6; Coris monspeliensis: 1076.9) or lower (Sedum sediforme: 15.7) than in any other species (the median of the rest of species: 151.8). We excluded these species from the analyses (Table S1, in Appendix S1), and the rest of the values were log-transformed to fulfill the assumptions of parametric statistics. The phylogenetic principal component analysis was performed using the functions "phyl. pca" and "scores" to obtain the PC scores for individuals based on a rotation computed for the species means, both functions in the "phytools" package (Revell 2012) in R version 3.6.1(R Core Team 2018). Hereafter, for simplicity, we refer to the phylogenetic principal component analysis as PCA.

We assembled the phylogenetic relationships among the plant species in the community with the R function "S.PhyloMaker" (Qian and Jin 2016), which uses an expanded version of the time-calibrated angiosperm species-level phylogeny (Zanne et al. 2014). Most of the studies and the statistical methods to assess the evolutionary conservatism of traits use a single trait value for each species, ignoring within-species variation (Ives et al. 2007). However, we used Ives et al. (2007) approach to take into account variation within species. Furthermore, we tried to maximize the intraspecific variation captured for each species by sampling the most contrasting situations representing abiotic versus biotic stress (i.e., plants growing alone vs. growing in vegetation patches, in a semi-arid community). Thus, we used the scores in the PC1 of the paired individuals (growing alone and in a vegetation patch) to calculate the mean and standard error (SE) for each species, and computed 
the phylogenetic signal based on the statistics Blomberg's K (Blomberg et al. 2003) following Ives etal. (2007). This test demonstrates correct Type I error rate and good power for simulated datasets with 20 or more species, and therefore it is appropriate despite our low sample size. This approach constructs a phylogenetic tree that combines the phylogenetic covariance among species with the intra-specific variation. It includes the later by elongating the terminal branches of the tree according to the value of the intra-specific variation relative to the variance of the evolutionary process. For three species (Thymus vulgaris, Plantago albicans, Brachypodium phoenicoides), some metabolites could not be quantified in some of the individuals (Table S1, in Appendix S1), preventing the calculation of the SE and their inclusion in this analysis. Statistical significance was assessed with 999 randomized repetitions using the function "phylosig" in the package "phytools" for $\mathrm{R}$ (Revell 2012). K values range from 0 to $\infty$, with values $K>0$ indicating the existence of a phylogenetic signal. Values between 0 and 1 indicate low trait conservatism and values higher than 1 are indicative of high (i.e., more than the expected under Brownian motion) phylogenetic signal.

\section{Results}

The content of the five metabolites was highly variable across the 30 studied species (Tables S1-S3, in Appendix S1). The first and second principal components of the PCA using the five metabolites explained a $40 \%$ and $24 \%$ of the total variance respectively (Fig. 1, scores of the first principal component in Table 1). The loadings of the five metabolites in the first principal component represent a combination concordant with different responses to biotic versus abiotic stress (Fig. 1). On one pole of the axis, the first principal component segregated the metabolites related with abiotic-stress response (loadings proline $=0.6$, and $\mathrm{ABA}=0.3$; Table S1 in Appendix S1). On the other pole of the axis were segregated the metabolites usually related to biotic stress tolerance (JA $=-0.9$ and $\mathrm{SA}=-0.5$; Table $\mathrm{S} 3$ in Appendix S1). Finally, a metabolite related to both types of stresses was located between the previously described extremes (IAA $=0.2$, Table S2) (Fig. 2). The distribution of samples scores along the PC1 was independent of the time of the day of each collection (i.e., hours since the first sample was collected: $\mathrm{F}=0.3, d f=1, p$-value $=0.6$ ).

When the mean and SE of the PC1 scores per species were considered, the species scores (i.e., strategy defined by each species) was phylogenetically conserved (i.e., significant phylogenetic signal, Blomberg's $\mathrm{K}=0.2, p$-value $=0.03$ ), indicating that close relatives tended to show a similar score, and thus a similar strategy regarding their investment in the 5 metabolites analyzed (Fig. 2).

\section{Discussion}

Plant responses to stress combinations result in emergent metabolic profiles that are unlikely predicted by the effect of individual stresses (De Vos et al. 2006; Makumburage etal.2013; Zandalinas et al. 2018). This might result in constrained physiological investments in stress tolerance when the plants face multiple stresses simultaneously. Our results show that in the studied community, plant species tradeoff their investment in abiotic-stress tolerance against their investment in biotic stress tolerance defining two metabolic strategies: some plant species tend to invest in abiotic stress-related metabolites (proline, ABA) 


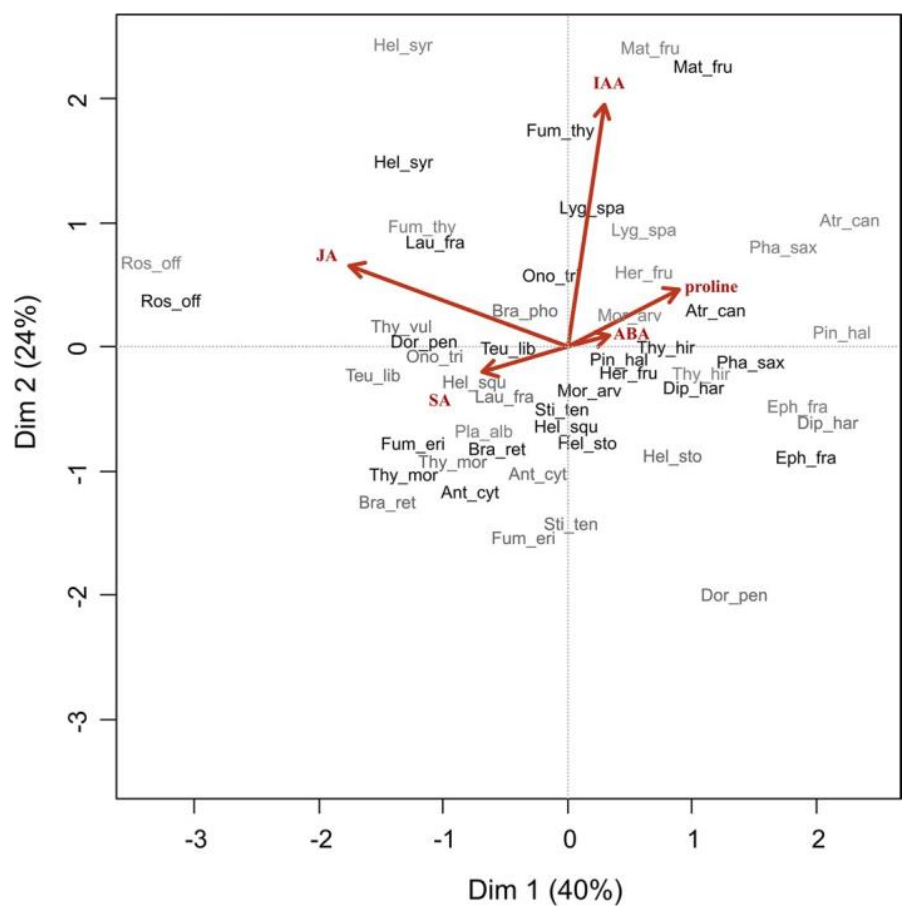

Fig. 1 First and second PCA axis explain 40\% and 24\% of the totalvariance. Metabolites used as variables in the PCA are: proline, abcisic acid (ABA), indole acetic acid (IAA), jasmonic acid (JA), and salicylic acid (SA). Each point corresponds to an individual and the code indicates the species (the first three letters of the genus and species name) and the color its position solitary (black) and associated (grey). Full names are presented in TableS1

while others tend to invest in biotic stress-related metabolites (JA and SA). Interestingly, these strategies seem to be evolutionarily conserved among the species that co-occur in this community, with close relatives tending to resemble each other (Fig. 2). The magnitude of such phylogenetic signal, although significant, was not very high, suggesting that despite being to some extent evolutionarily constrained, the metabolic strategy also had some flexibility. Inaddition, it is worth to highlight that this study is community focused (with alimited number of species), and therefore does not intend to draw a general conclusion about a phylogenetic constraint through the whole phylogeny of angiosperms. On the contrary, it shows that when we consider the set of species that had overcome a shared combination of filters to establish in a given environment, they show evolutionarily conserved strategies to deal with biotic/abiotic stresses.

Plant species might deal with physiological constraints to respond to both abiotic and biotic stresses, as for instance, responses involving ABA pathway (associated with abiotic stress) can be influenced by theSA or JA pathways (associated with biotic stress) (Anderson et al. 2004; Fujita et al. 2006; De Torres Zabala et al. 2009; Kissoudis et al. 2015; Ximénez-Embún et al. 2018). Potential tradeoffs between the plants' investment in their responses to abiotic versus biotic stresses have been mainly approached the individual (or within species) level (Eränen et al. 2009; Ariga et al. 2017; Berens et al. 2019), but as far as we know, this is the firstattempt to consider it at a macroevolutionary scale, testing 
Table 1 Individual scores in the principal component analysis. Species mean and standard error (SE) are also presented. Negative values indicate a higher investment in abiotic relative to biotic stress-related metabolites

\begin{tabular}{|c|c|c|c|c|}
\hline \multirow[t]{2}{*}{ Species } & \multirow{2}{*}{$\begin{array}{l}\text { Solitary (S) } \\
\text { PC1 }\end{array}$} & \multirow{2}{*}{$\begin{array}{l}\text { Associated (A) } \\
\text { PC1 }\end{array}$} & \multicolumn{2}{|l|}{ Species } \\
\hline & & & Mean & SE \\
\hline Rosmarinus officinalis & -3.13 & -3.40 & -3.26 & 0.14 \\
\hline Thymus vulgaris & - & - & - & - \\
\hline Thymus moroderi & -1.25 & -0.89 & -1.07 & 0.18 \\
\hline Teucrium libanitis & -0.41 & -1.49 & -0.95 & 0.54 \\
\hline Plantago albicans & - & - & - & - \\
\hline Helichrysum stoechas & 0.23 & 0.92 & 0.57 & 0.34 \\
\hline Phagnalon saxatile & 1.55 & 1.82 & 1.68 & 0.13 \\
\hline Santolina chamaecyparissus & - & - & - & - \\
\hline Launaea fragilis & -0.99 & -0.43 & -0.71 & 0.28 \\
\hline Atractylis cancellata & 1.26 & 2.34 & 1.80 & 0.54 \\
\hline Coris monspeliensis & - & - & - & - \\
\hline Herniaria fruticosa & 0.56 & 0.69 & 0.62 & 0.07 \\
\hline Ononis tridentata & -0.07 & -0.99 & -0.53 & 0.46 \\
\hline Dorycnium pentaphyllum & -1.08 & 1.41 & 0.17 & 1.24 \\
\hline Anthyllis cytisoides & -0.71 & -0.16 & -0.44 & 0.28 \\
\hline Helianthemum squamatum & 0.04 & -0.67 & -0.31 & 0.35 \\
\hline Helianthemum syriacum & -1.24 & -1.25 & -1.25 & 0.01 \\
\hline Fumana thymifolia & 0.01 & -1.09 & -0.54 & 0.55 \\
\hline Fumana ericoides & -0.84 & -0.28 & -0.56 & 0.28 \\
\hline Thymelaea hirsuta & 0.77 & 1.14 & 0.96 & 0.18 \\
\hline Diplotaxis harra & 1.09 & 2.17 & 1.63 & 0.54 \\
\hline Moricandia arvensis & 0.21 & 0.58 & 0.39 & 0.18 \\
\hline Matthiola fruticulosa & 1.16 & 0.74 & 0.95 & 0.21 \\
\hline Sedum sediforme & - & - & - & - \\
\hline Stipa tenacissima & 0.02 & 0.11 & 0.06 & 0.04 \\
\hline Brachypodium phoenicoides & - & - & - & - \\
\hline Brachypodium retusum & -0.50 & -1.38 & -0.94 & 0.44 \\
\hline Lygeum spartum & 0.27 & 0.69 & 0.48 & 0.21 \\
\hline Pinus halepensis & 0.49 & 2.28 & 1.38 & 0.89 \\
\hline Ephedra fragilis & 1.99 & 1.92 & 1.96 & 0.04 \\
\hline
\end{tabular}

for an evolutionary conservatism of the tradeoff across co-occurring species. Our analyses take into account intra-specific variation by sampling two individuals in contrasting environments, which may not be sufficient to capture the extent of intraspecific variation in metabolic responses fully, but may be a broad approximation of the maximum withinspecies variation. A deeper characterization of intraspecific variation will allow assessing potential phylogenetic patterns in species' plasticity when multiple individuals of the same species are exposed to a wider diversity of ecological contexts varying in their balance of biotic/abiotic stresses. Some studies have explored the evolutionary conservatism of plastic responses for instance considering phenology shifts (Rafferty and Nabity 2017), but this is 


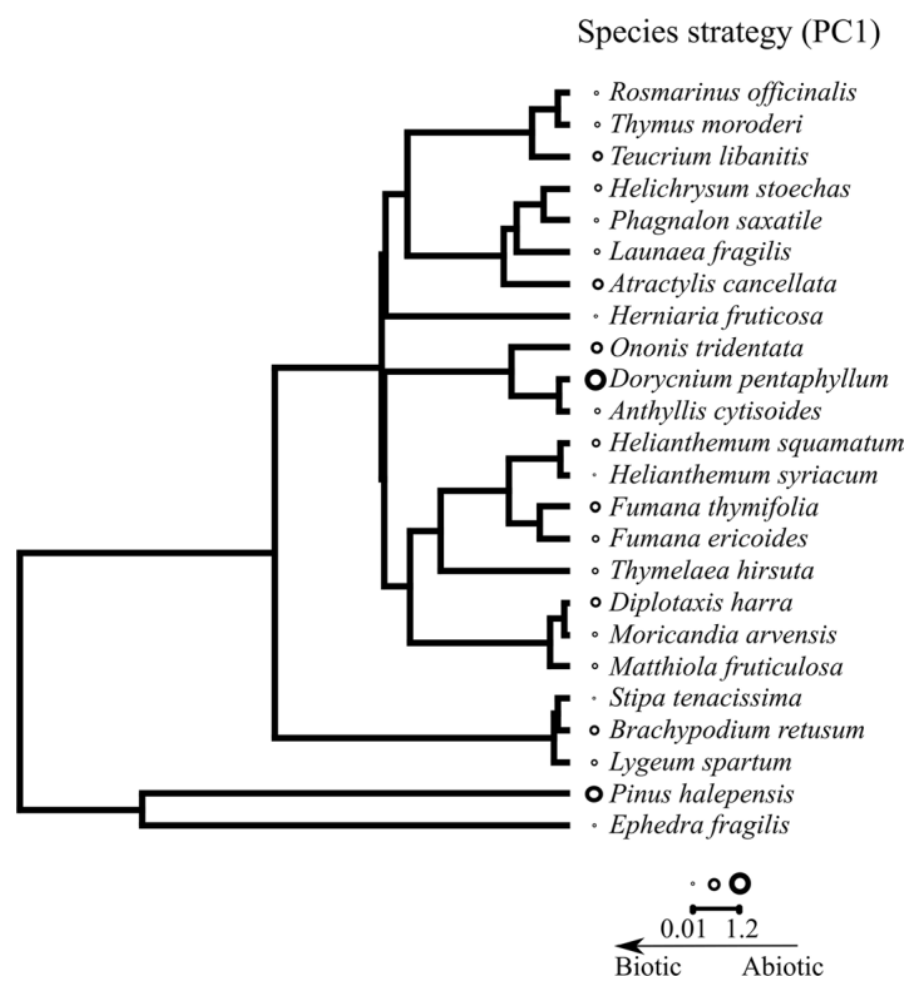

Fig. 2 Phylogenetic conservatism of plant species strategies, measured as the mean value of the PC1 scores per species. PC1 axis segregated species investing in metabolites related with abiotic versus biotic-stress tolerance as shown in the bottom legend

a far unexplored topic regarding plant metabolic responses to multiple stresses. Despite the intraspecific variation in metabolite contents resulting from our sampling, under contrasting environmental conditions, our results show that the sampled individuals of the same species tend to have similar metabolic strategies and close relatives resemble each other in their metabolic strategy. Similar phylogenetic patterns have been found showing shared metabolic responses to folivory between species within the same genus (Rivas-Ubach et al. 2016b; 2017), or unique and conserved metabolic responses to drought stress levels within species belonging to the same family (Sanchez et al. 2012). Further research exploring whether the intraspecific trade-off in the investment to respond to biotic/abiotic stresses is also evolutionarily conserved, may contribute to a further understanding of these evolutionary processes.

The application of profiling techniques to plant physiology and ecology has revealed considerable plasticity of metabolomes under different ecological contexts (Sardans et al. 2011; Rivas-Ubach et al. 2012; 2016a). Understanding the phylogenetic contributions of the metabolome is critical in the current context of global change (Edwards et al. 2007; Kuntner et al. 2014; González-Orozco et al. 2016), as the underlying mechanisms can be important to predict the potential of plants to respond to different ecological scenarios.

Acknowledgements AMN was supported by a postdoctoral contract from the Spanish Ministry of Economy and Competitiveness (IJCI-2015-23498). RSM was supported by the Ministry of education and professional 
training, Spain (FPU Grant FPU17/00629). Financial support was provided by the Spanish Ministry of Economy and Competitiveness (RTI2018-099672-J-I00, AGL2016-76574-R). Hormone measurements were carried out at the central facilities (Servei Central d'Instrumentació Científica,SCIC) of the Universitat Jaume I. The Sapiencia Association and the Sanwei place facilitated and promoted the discussions that originated this work.

Author Contributions AGC, MV and AMN planned and designed the research. AMN and RSM conducted fieldwork, RMPC and AGC performed the chemical analyses, AMN analyzed data. AMN wrote the first draft of the manuscript and all the authors contributed to the final version.

\section{Compliance with ethical standards}

Conflict of interest The authors declare that they have no conflicts of interest.

\section{References}

Ackerly DD (2003) Community assembly, niche conservatism, and adaptive evolution in changing environments. Int J Plant Sci 164:S165-S184

Anacker BL, Klironomos JN, Maherali H, Reinhart KO, Strauss SY (2014) Phylogenetic conservatism in plant-soil feedback and its implications for plant abundance. Ecol Lett 17:1613-1621

Anderson JP, Badruzsaufari E, Schenk PM, Manners JM, Desmond OJ, Ehlert C et al (2004) Antagonistic interaction between abscisic acid and jasmonate-ethylene signaling pathways modulates defense gene expression and disease resistance in Arabidopsis. Plant Cell 16:3460-3479

Ariga H, Katori T, Tsuchimatsu T, Hirase T, Tajima Y, Parker JE et al (2017) NLR locus-mediated trade-off between abiotic and biotic stress adaptation in Arabidopsis. Nat Plants 3:17072

Bates LS, Waldren RP, Teare I (1973) Rapid determination of free proline for water-stress studies. Plant Soil 39:205-207

Berens ML, Wolinska KW, Spaepen S, Ziegler J, Nobori T, Nair A et al (2019) Balancing trade-offs between biotic and abiotic stress responses through leaf age-dependent variation in stress hormone cross-talk. Proc Natl Acad Sci 116:2364-2373

Blomberg SP, Garland JT, Ives AR, Crespi B (2003) Testing for phylogenetic signal in comparative data: behavioral traits are more labile. Evolution 57:717-745

Bosch M, Wright LP, Gershenzon J, Wasternack C, Hause B, Schaller A, Stintzi A (2014) Jasmonic acid and its precursor 12-oxophytodienoic acid control different aspects of constitutive and induced herbivore defenses in tomato. Plant Physiol 166:396-410

CaraDonna PJ, Inouye DW (2015) Phenological responses to climate change do not exhibit phylogenetic signal in a subalpine plant community. Ecology 96:355-361

Chang-Yang CH, Sun IF, Tsai CH, Lu CL, Hsieh CF (2016) ENSO and frost codetermine decade-long temporal variation in flower and seed production in a subtropical rain forest. J Ecol 104:44-54

Chen L, Zheng Y, Gao C, Mi XC, Ma KP, Wubet T, Guo LD (2017) Phylogenetic relatedness explains highly interconnected and nested symbiotic networks of woody plants and arbuscular mycorrhizal fungi in a Chinese subtropical forest. Mol Ecol 26:2563-2575

Delalandre L, Montesinos-Navarro A (2018) Can co-occurrence networks predict plant-plant interactions in a semi-arid gypsum community? Perspect Plant Ecol Evol Syst 31:36-43

Durgbanshi A, Arbona V, Pozo O, Miersch O, Sancho JV, Gómez-Cadenas A (2005) Simultaneous determination of multiple phytohormones in plant extracts by liquid chromatographyelectrospray tandem mass spectrometry. J Agric Food Chem 53:8437-8442

De Vos M, Van Zaanen W, Koornneef A, Korzelius JP, Dicke M, Van Loon L et al (2006) Herbivoreinduced resistance against microbial pathogens in Arabidopsis. Plant Physiol 142:352-363

De Torres ZM, Bennett MH, Truman WH, Grant MR (2009) Antagonism between salicylic and abscisic acid reflects early host-pathogen conflict and moulds plant defence responses. Plant J 59:375-386

Dobra J, Motyka V, Dobrev P, Malbeck J, Prasil IT, Haisel D, Gaudinovaa A, Havlovaa M, Gubis J, Vankova $\mathrm{R}$ (2010) Comparison of hormonal responses to heat, drought and combined stress in tobacco plants with elevated proline content. J Plant Physiol 167:1360-1370

Edwards EJ, Still CJ, Donoghue MJ (2007) The relevance of phylogeny to studies of global change. Trends Ecol Evol 22:243-249 
Epstein E, Ludwig-MüllerJ (1993) Indole-3-butyric acid in plants: occurrence, synthesis, metabolism and transport. Phys Plantarum 88:382-389

Eränen J, Nilsen J,ZverevV,Kozlov M (2009) Mountain birch under multiple stressors-heavy metal-resistant populations co-resistant to biotic stress but maladapted to abiotic stress. J Evol Biol 22:840-851

Erb M, Meldau S, Howe GA (2012) Role of phytohormones in insect-specific plant reactions. Trends Plant Sci 17:250-259

Foronda A, Pueyo Y, Arroyo AI, Saiz H, de la Luz GM, Alados CL (2019) The role of nurse shrubs on the spatial patterning of plant establishment in semi-arid gypsum plant communities. JArid Environ 160:82-90

Fujita M, Fujit Y, Noutoshi Y, Takahashi F, Narusaka Y, Yamaguchi-Shinozaki K et al (2006) Crosstalk between abiotic and biotic stress responses: a current view from the points of convergence in the stress signaling networks. Curr Opin Plant Biol 9:436-442

Gastauer M, Saporetti-Junior AW,Valladares F, Meira-Neto JA (2017) Phylogenetic community structure reveals differences in plant community assembly of an oligotrophic white-sand ecosystem from the Brazilian Atlantic Forest. Acta Bot Brasilica 31:531-538

Gilbert GS, Webb CO (2007) Phylogenetic signal in plant pathogen-host range. Proc Natl Acad Sci 104:4979-4983

Glazebrook J (2005) Contrasting mechanisms of defense against biotrophic and necrotrophic pathogens. Ann Rev Phytopathol 43:205-227

Gómez JM, Verdú M, Perfectti F (2010) Ecological interactions are evolutionarily conserved across the entire tree of life. Nature 465:918-921

Gómez-Cadenas A, Vives V,Zandalinas SI, Manzi M, Sanchez-Perez AM, Perez-Clemente RM, Arbona V (2015) Abscisic acid: a versatile phytohormone in plant signaling and beyond-current. Protein Peptide Sci 16:413-434

González-Orozco CE, Pollock LJ, Thornhill AH, Mishler BD, Knerr N, Laffan SW et al (2016) Phylogenetic approaches reveal biodiversity threats under climate change. Nat Clim Change 6:1110

Guan C, Cen HF, Cui X, Tian DY, Tadesse D, Zhang YW (2019) Proline improves switchgrass growth and development by reduced lignin biosynthesis. Sci Rep 9:1-8

Hartmann M, Zeier J (2019) N-Hydroxypipecolic acid and salicylic acid: a metabolic duo for systemic acquired resistance. Curr Opin Plant Biol 50:44-57

Hersh MH, Vilgalys R, Clark JS (2012) Evaluating the impacts of multiple generalist fungal pathogens on temperate tree seedling survival. Ecology 93:511-520

Ives AR, Midford PE, Garland T (2007) Within-species variation and measurement error in phylogenetic comparative methods. Syst Biol 56:252-270

Kissoudis C, Chowdhury R, van Heusden S, van de Wiel C, Finkers R, Visser RG et al (2015) Combined biotic and abiotic stress resistance in tomato. Euphytica 202:317-332

Klessig DF, Choi HW,Dempsey DMA (2018) Systemic acquired resistance and salicylic acid: past, present, and future. Mol Plant-microbe Interact 31:871-888

Kluger CG, Dalling JW, Gallery RE, Sanchez E, Weeks-Galindo C, Arnold AE (2008) Host generalists dominate fungal communities associated with seeds of four neotropical pioneer species. J Trop Ecol 24:351-354

Kuntner M, Nuapuarucs M, Li D, Coddington JA (2014) Phylogeny predicts future habitat shifts due to climate change. PLoS ONE 9:e98907

Li X, Pei K, Kery M, Niklaus PA, Schmid B (2017) Decomposing functional trait associations in a Chinese subtropical forest. PLoS ONE 12(4):e0175727

Makumburage GB, Richbourg HL, LaTorre KD, Capps A, Chen C, Stapleton AE (2013) Genotype to phenotype maps: multiple input abiotic signals combine to produce growth effects via attenuating signaling interactions in maize. G3 Genes Genom Genet 3:2195-2204

Montesinos-Navarro A, Segarra-Moragues JG, Valiente-BanuetA,Verdú M(2012) Plant facilitation occurs between species differing in their associated arbuscular mycorrhizal fungi. New Phytol 196:835-844

Munemasa S, Hauser F, Park J, Waadt R, Brandt B, Schroeder JI (2015) Mechanisms of abscisic acid-mediated control of stomatal aperture. Curr Opin Plant Biol 28:154-162

Münkemüller T, Boucher FC, Thuiller W, Lavergne S (2015) Phylogenetic niche conservatism-common pitfalls and ways forward. Funct Ecol 29:627-639

Novotny V, Basset Y (2005) Host specificity of insect herbivores in tropical forests. Proc R Soc B Biol Sci 272:1083-1090

Nagahama A, Yahara T (2019) Quantitative comparison of flowering phenology traits among trees, perennial herbs, and annuals in a temperate plant community. Am J Botany 106:1545-1557

Pearse IS, Aguilar J, Schroder J, Strauss SY (2017) Macroevolutionary constraints to tolerance: trade-offs with drought tolerance and phenology, but not resistance. Ecology 98:2758-2772 
Pihain M, Gerhold P, Ducousso A, Prinzing A (2019) Evolutionary response to coexistence with close relatives: increased resistance against specialist herbivores without cost for climatic-stress resistance. Ecol Lett 22:1285-1296

Qian H, Jin Y (2016) An updated megaphylogeny of plants, a tool for generating plant phylogenies and an analysis of phylogenetic community structure. J Plant Ecol 9:233-239

R Core Team (2018) R: A language and environment for statistical computing R Foundation for Statistical Computing. Vienna, Austria, https://www.R-project.org/

Rafferty NE, Nabity PD (2017) A global test for phylogenetic signal in shifts in flowering time under climate change. J Ecol 105:627-633

Revell LJ (2009) Size-correction and principal components for interspecific comparative studies. Evolution 63:3258-3268

Revell LJ (2012) Phytools: an R package for phylogenetic comparative biology (and other things). Methods Ecol Evol 3:217-223

Ristok C, Poeschl Y, Dudenhöffer JH, Ebeling A, Eisenhauer N, Vergara F et al (2019) Plant species richness elicits changes in the metabolome of grassland species via soil biotic legacy. J Ecol 107:2240-2254

Rivas-Ubach A, Barbeta A, Sardans J, Guenther A, Ogaya R, Oravec M et al (2016a) Topsoil depth substantially influences the responses to drought of the foliar metabolomes of Mediterranean forests. Perspect PlantEcol Evol Syst 21:41-54

Rivas-Ubach A, Hódar JA, Sardans J, Kyle JE, Kim Y-M, Oravec M et al (2016b) Are the metabolomic responses to folivory of closely related plant species linked to macroevolutionary and plant-folivore coevolutionary processes? Ecol Evol 6:4372-4386

Rivas-Ubach A, Sardans J, Hódar JA, Garcia-Porta J, Guenther A, Pavsa-Tolic L et al (2017) Close and distant: contrasting the metabolism of two closely related subspecies of Scots pine under the effects of folivory and summer drought. Ecol Evol 7:8976-8988

Rivas-Ubach A, Sardans J, Pérez-Trujillo M, Estiarte M, Peñuelas J (2012) Strong relationship between elemental stoichiometry and metabolome in plants. Proc Natl Acad Sci 109:4181-4186

Salazar A, Maschinski J, Possley J, Heineman K (2018) Seed germination of 53 species from the globally critically imperiled pine rockland ecosystem of South Florida, USA: effects of storage, phylogeny and life-history traits. Seed Sci Res 28:82-92

Sanchez DH, Schwabe F, Erban A, Udvardi MK, Kopka J (2012) Comparative metabolomics of drought acclimation in model and forage legumes. Plant Cell Environ 35:136-149

Sah SK, Reddy KR, Li J (2016) Abscisic acid and abiotic stress tolerance in crop plants. Front Plant Sci 7:571

Sardans J, Penuelas J, Rivas-Ubach A (2011) Ecological metabolomics: overview of current developments and future challenges. Chemoecology 21:191-225

Simpson KJ, Ripley BS, Christin PA, Belcher CM, Lehmann CE, Thomas GH, Osborne CP (2016) Determinants of flammability in savanna grass species. J Ecol 104:138-148

Spear ER, Mordecai EA (2018) Foliar pathogens are unlikely to stabilize coexistence of competing species in a California grassland. Ecology 99:2250-2259

Thoen MP, Davila Olivas NH, Kloth KJ, Coolen S, Huang PP, Aarts MG, Bac-Molenaar JA, Bakker J, Bouwmeester HJ, Broekgaarden C et al (2017) Genetic architecture of plant stress resistance: multi-trait genome-wide association mapping. New Phytol 213:1346-1362

Webb CO, Ackerly DD, McPeek MA, Donoghue MJ (2002) Phylogenies and community ecology. Ann Rev Ecol Syst 33:475-505

Werner GD, Cornwell WK, Sprent JI, Kattge J, Kiers ET (2014) A single evolutionary innovation drives the deep evolution of symbiotic N 2-fixation in angiosperms. Nat Commun 5:1-9

Ximénez-Embún MG, González-Guzmán M, Arbona V, Gómez-Cadenas A, Ortego F, Castañera P (2018) Plant-mediated effects of water deficit on the performance of Tetranychus evansi on tomato droughtadapted accessions. Front Plant Sci 9:1490

Zandalinas SI, Mittler R, Balfagón D, Arbona V, Gómez-Cadenas A (2018) Plant adaptations to the combination of drought and high temperatures. Physiol Plantarum 4:427-438

Zanne AE, Tank DC, Cornwell WK, Eastman JM, Smith SA, FitzJohn RG et al (2014) Three keys to the radiation of angiosperms into freezing environments. Nature 506:89-92

Publisher's Note Springer Nature remains neutral with regard to jurisdictional claims in published maps and institutional affiliations. 


\section{Affiliations}

Alicia Montesinos-Navarro ${ }^{1}$ Rosa M. Pérez-Clemente ${ }^{2} \cdot$ Ricardo Sánchez-Martín $^{1}$. Aurelio Gómez-Cadenas ${ }^{2} \cdot$ Miguel Verdú ${ }^{1}$

Rosa M. Pérez-Clemente

rosa.perez@uji.es

Ricardo Sánchez-Martín

ricardo.sanchez@uv.es

Aurelio Gómez-Cadenas

aurelio.gomez@uji.es

Miguel Verdú

Miguel.Verdu@ext.uv.es

${ }^{1}$ Centro de Investigaciones Sobre Desertificación (CIDE, CSIC-UV-GV), Carretera de Moncada-Náquera, Km 4.5, 46113 Moncada, Valencia, Spain

${ }^{2}$ Departament de Ciències Agràries I del Medi Natural, Universitat Jaume I, Avda. Sos Baynat s/n, 12071 Castellón de la Plana, Spain 